\title{
Understanding the Dynamics of Staff Reallocation to Clinical Practice During the First Wave of COVID-19 - a Qualitative Study
}

Rie Laurine Rosenthal Johansen ( $\sim$ rie.laurine.rosenthal.johansen@regionh.dk )

Bispebjerg and Frederiksberg University Hospital

\section{Anita Sørensen}

Bispebjerg and Frederiksberg University Hospital

\section{Mads Seit Jespersen}

Bispebjerg and Frederiksberg University Hospital

\section{Kamilla Hesthaven Mikkelsen}

Bispebjerg and Frederiksberg University Hospital

Christina Emme

Bispebjerg and Frederiksberg University Hospital

\section{Research Article}

Keywords: COVID-19, pandemic, reallocation, healthcare worker, hospital contingency plan, implementation, qualitative study, leadership

Posted Date: January 10th, 2022

DOI: https://doi.org/10.21203/rs.3.rs-1187927/v1

License: (a) (i) This work is licensed under a Creative Commons Attribution 4.0 International License. Read Full License 


\section{Abstract}

\section{Background}

During the COVID-19 pandemic, one responsive strategy to ensure hospital staff capacity was reallocation of staff between departments. Unpredicted factors may influence how the strategy is executed.

Knowledge of potential moderating factors is essential to improve future staff contingency plans. To understand barriers and promoters of staff realloctation, this study explored the dynamics of reallocating staff from departments with low activity to clinical practice during the first wave of the COVID-19 pandemic at a 530-bed university hospital in the Capital Region of Denmark.

\section{Methods}

We used a mixed-methods explanatory design with sequential data collection and analysis. This paper primarily describes the qualitative part of the study, which consisted of six interviews with staff reallocated to clinical practice as part of the staff contingency plan, and seven interviews with leaders of departments that contributed with staff for reallocation. Data was analyzed using inductive content analysis.

\section{Results}

The results showed that the execution of a staff contingency plan during a pandemic is influenced by a complex set of structural, perceptional, social, individual, and psychological moderating factors. Although staff felt obligated and motivated to cover shifts, their actual behavior and experience was influenced by factors such as uncertainty about tasks, family obligations, other work-related tasks, the contingency plan set-up, how the contingency plan, roles, and sense of urgency were interpreted by staff and leaders, and how the leaders prioritized tasks and staff time. Introduction to the unit and tasks, the feeling of being needed, voluntary participation, transparency, collegial sparring, and familiarity with the workplace were factors that promoted a positive experience.

\section{Conclusions}

This study identified a variety of complex moderating factors, which should be considered when hospital contingency plans are developed. The study highlights the importance of understanding how reallocated staff and leaders experience and make interpretations and adjustments to a given plan, as this may have great significance for how the contingency plan is put into practice. Future staff contingency plans should take these factors into consideration to make better use of human resources in times of a crisis and to improve staff's experience with reallocation.

\section{Background}

As the COVID-19 pandemic escalated in Denmark in March 2020, hospitals quickly had to take measures to prevent staff shortages (1). Not only could the pandemic result in an increased demand for patient care, 
but also a decrease in capacity due to clinical staff being infected $(2,3)$. A successful staff contingency plan is pivotal to prevent the health care system from collapsing during a crisis such as the COVID-19 pandemic (4). In order to ensure capacity to deliver treatment and care for patients, one responsive strategy is reallocation of staff between departments. However, although this strategy seems possible and sensible in theory, it may work differently when put into practice. Unpredicted factors may influence how the strategy is executed, and knowledge of such potential moderating factors is essential to improve future staff contingency plans (3).

Previous studies have perceived the willingness and ability to work as the main determinants of staff working behavior during a pandemic $(3,5)$. In a meta-analysis, estimates on the percentage of staff willing to work during a possible influenza pandemic varied between $23.1 \%$ and $95.8 \%$ (3). Willingness and ability to work during a pandemic has previously been found to be influenced by a wide range of factors, such as demographics, risk perception and fear of infections, confidence in personal skills and prior training, social norms, and sense of responsibility, role importance, expectations about workload and possible quarantine, environmental constraints, such as lack of personal protective equipment (PPE), family obligations, and previous experience with pandemics. $(3,5)$. However, many previous studies are based on surveys concerning expectations about reporting to work during a pandemic, and several are based on hypothetical pandemics $(3,5)$. Furthermore, most studies have focused on individual barriers and have not included organizational factors $(3,5)$. Some qualitative studies have been conducted, giving a more in-depth understanding of staff's willingness and ability to work, but most studies focus only on medical staff (5).

To ensure staff capacity in Denmark during the first wave of COVID-19, elective treatments, ambulatory care, and research were downscaled to release staff to acute care (1). At Bispebjerg and Frederiksberg Hospital in the Capital Region of Denmark, a staff contingency plan was formulated and implemented. Staff from departments with low or non-clinical activities were reallocated to a staff floating pool, managed by the hospital's nurse floating pool. The staff were mainly doctors working in research or specialized in occupational or social medicine, physiotherapists, pharmacists, or staff working in paraclinical departments. Staff with recent clinical experience were assigned to clinical functions corresponding to a newly educated doctor or nurse. They were either reallocated to a bed unit with COVID19 patients, or the hospital's Corana test center. Staff with little or no medical experience were assigned a new function as 'Runner', 'Cleaner', 'Foodie' or 'Mixer' - functions created for the COVID-19 situation. The Runners provided staff with the necessary equipment in the patient rooms, enabling the staff to stay with the patients and to economize the use of personal protective equipment (PPE). The Cleaners continuously cleaned exposed areas to decrease the spread of infection, and the Foodies served meals to the patients. Mixers were in charge of dispensing medicine. These services aimed to release the regular staff and provide time for their key task; patient care. The board of directors asked all departments with low or nonclinical activities to identify staff that could be reallocated to the staff floating pool and perform the new job functions. To prepare the staff for their new tasks they participated in a one-day course to learn about COVID-19, the hospital's staff contingency plan, and to refresh basic clinical skills, as well as how to use PPE. 
At hospital level, there was an expectation that it would be possible to reallocate numerous staff. However, it quickly became apparent that less staff than expected were reallocated during the first wave of the COVID-19 pandemic.

In this study we explore the dynamics of a staff contingency plan from a staff and leadership perspective during an ongoing COVID-19 pandemic to better understand barriers and promoters of staff reallocation. This allows us to go beyond self-reported expectations and study the actual execution of the staff contingency plan and identify situation-related moderating factors, providing a better understanding of the gap between reallocation as planned and reallocation as done.

\section{Aim}

This study aims to explore the dynamics of reallocating staff to clinical practice during the first wave of COVID-19 in order to make better use of human resources, and improve staff experience with reallocation in case of a new and similar crisis.

\section{Methods}

\section{Setting}

Our study took place at a 530-bed university hospital in the Capital Region of Denmark. The hospital attends to 80,000 acute and elective patients and has more than 400,000 outpatient visits per year and includes ten different clinical departments and a nurse floating pool. In addition, the hospital includes departments such as Department of Occupational Medicine, Department Physiotherapy and Occupational Therapy, and various research centers. During the first wave of COVID-19 the hospital established a bed section for patients with coronavirus and a test center for patients who were referred to medical evaluation or test due to suspicion of COVID-19.

\section{Design}

We chose a mixed-methods design because it provides tools for exploring complex processes and systems (6). We applied an explanatory design (participant selection model) with sequential data collection and analysis, focusing on the qualitative analysis (7). This paper primarily describes the qualitative part of the study, enabling us to understand and explore unchartered areas (8).

The study design consisted of three parts; 1) A survey that was distributed to all staff participating in the 1-day preparation course, 2) interviews with staff who were reallocated to the hospitals' floating pool as part of the staff contingency plan, and 3) interviews with leaders of the departments that contributed with staff for reallocation.

The part of the study concerning the reallocated staff was inspired by Brinkerhoff's 'Success Case Method' (SCM), which originally was developed for evaluating the business effect of educational programs (9). According to Brinkerhoff, it is important to identify what works and what does not, in order 
to improve a given effort (10). Furthermore, Brinkerhoff's method is interesting as it is more concerned with the knowledge you can obtain from studying the extremes instead of the mean. SCM consists of two steps: 1) a survey which aims at identifying potential successes and non-successes, 2) individual semistructured interviews with selected successes and non-success, aiming at exploring which initiatives contributed to or hindered success (9). SCM has previously been applied in evaluating educational interventions in the health sector (11-13). In this study we used SCM to select the informants and design the interview guide for the reallocated staff.

\section{The survey}

The staff who participated in the hospital's 1-day preparation course received an online survey one month after the course. A total of 174 hospital workers participated in the one-day course, and 103 (59\%) completed the online survey. Of those who completed the survey, 71 were employed at a department with low activity due to COVID-19 and participated in the hospital floating pool. A total of $55 \%$ of the staff were doctors, $13 \%$ were pharmacists, $8 \%$ were physiotherapist, $7 \%$ were nurses, and $4 \%$ were bioanalysts.

Within the preceding month after participating in the one-day course, $42(59 \%)$ had one or more shifts in a clinical department. The number of shifts per worker ranged from 0-20, with a median of 2.

One of the purposes of the survey was to help the researchers identify and purposefully select the eligible informants for the qualitative part of the study. We selected the staff based on their reply to the question: "Overall, how would you rate your experience with handling a different function than usual?". The staff were asked to reply on a scale from 1-6, with one meaning "very poor" and six meaning "very good"). According to the replies, five respondents $(11 \%)$ had a poor or very poor experience (response category 1 or 2), whereas 11 respondents (18\%) had a very good experience (response category 6 ). In accordance with Brinkerhoff's Success Case Method (9), we selected eligible informants with replies indicating the most successful experience with being reallocated to clinical practice and the staff indicating the most unsuccessful experience. In order to obtain a wide variety in our material, the informants were also selected based on their assigned new function and their usual job function. Consequently, we invited ten members of the staff to participate in the interview study.

\section{Interviews with reallocated staff}

We conducted individual semi-structured interviews (14) with selected reallocated staff. In line with Brinkerhoff's Success Case Method $(9,10)$, we developed two separate interview guides; one for the staff with a successful experience (successes) and one for the staff with an unsuccessful experience (nonsuccesses). The interview guide for the staff with the most successful experience included: which factors contributed to the reallocation being a positive experience, their own experienced contribution, what made them feel safe in their new function, and barriers, if any, in relation to managing the new function. The interview guide for the staff with an unsuccessful experience included; what went wrong, contributing factors for the unsuccessful experience, and barriers for managing the new function. We asked both groups for improvement suggestions. A pilot test of the interviews guides was not conducted prior to the interviews. 
The informants chose the setting for the interviews. Therefore, some interviews were conducted at the informants' department, whereas others took place in the researchers' department or online. Two female members of the research team (RLRJ and CE) conducted the interviews, both experienced with qualitative methods. During all interviews, one of the two members observed the interview and took field notes. All interviews were audio-recorded. However, full transcription was not conducted due to limited resources. Instead, selective transcription was performed, picking out relevant passages and noting the tape counter numbers to mark quotations (15).

\section{Interviews with leaders}

We asked the leaders of all eight departments which reallocated staff to participate in the study. The interviews were semi-structured, based on an interview guide developed by and discussed in the research team. The interview guide consisted of four main questions and supporting questions concerning the leaders' reflections on the reallocation of their staff to clinical practice and handling COVID-19 related tasks. The leaders chose the setting for the interviews. Most interviews were conducted at the leader's office, and one was performed online.

\section{Ethical considerations}

The informants received an email invitation with information about the study. Before the interview, they also received oral information and signed a consent form. According to Danish law, only biomedical research requires permission from the Regional Scientific Ethical Committee. Furthermore, the research group requested permission from the Danish Data Protection Agency, but this was not required.

In order to respect the informants' anonymity, we replaced their names with codes in the data (e.g. S1). We coded leaders as L1-L8.

\section{Analysis}

We analyzed the data using inductive content analysis (16). The researchers conducting the interviews initiated the analysis by listening to the recordings of the first interview together, making sense of the data, and then performed open coding. The initial codes were discussed and elaborated on, with the initial grouping of the data. Next, the two researchers listened to and coded the remaining interviews separately and subsequently, the two researchers discussed and merged their codes, resulting in mutual categorization and abstraction. An example of the analysis process is illustrated in the coding tree (see Table 1). Data saturation, results, and abstraction were discussed with the research team. No software was applied to manage the data. The informants were not given the opportunity to provide feedback on the findings. 
Table 1

example of coding tree

\begin{tabular}{|llll|}
\hline Data & Code & Subcategory & Category \\
\hline $\begin{array}{l}\text { "It also made me feel confident that there was always } \\
\text { a doctor in the ward with whom you could discuss the } \\
\text { patients. I felt that everybody was very forthcoming. }\end{array}$ & $\begin{array}{l}\text { Always } \\
\text { somebody } \\
\text { to ask }\end{array}$ & $\begin{array}{l}\text { Collegial } \\
\text { sparring } \\
\text { partners } \\
\text { creates } \\
\text { cometimes the medical specialists also asked me for }\end{array}$ & $\begin{array}{l}\text { Psychological } \\
\text { factors }\end{array}$ \\
$\begin{array}{l}\text { advice. And sometimes I asked them. There was a } \\
\text { constant exchange of information" }\end{array}$ & & \multicolumn{1}{|l}{} \\
$\begin{array}{ll}\text { "I have always felt supported when I was in these } \\
\text { departments. And you can always ask. I'm not afraid } \\
\text { of asking." }\end{array}$ & $\begin{array}{l}\text { Not being } \\
\text { afraid to } \\
\text { ask } \\
\text { questions }\end{array}$ \\
\hline
\end{tabular}

\section{Results}

We conducted interviews with leaders from seven of the eight departments as one leader did not respond to the invitation. One department had shared leadership, and consequently, we interviewed both leaders together. Six of ten invited staff participated in the study; three did not respond to the invitation and one cancelled at the last minute. We conducted the interviews between May 28th and July 6th 2020. The interviews with both leaders and staff had a mean duration of 21 minutes (range 17-31 for leaders and range 18-27 minutes for staff). For further information about the staff see Table 2. 
Table 2

Staff characteristics

\begin{tabular}{|c|c|c|c|c|c|c|}
\hline ID & $\begin{array}{l}\text { Age } \\
\text { (years) }\end{array}$ & Usual job function & $\begin{array}{l}\text { Years since } \\
\text { participating } \\
\text { in clinical } \\
\text { practice }\end{array}$ & $\begin{array}{l}\text { Assigned new } \\
\text { function }\end{array}$ & $\begin{array}{l}\text { No. of shifts } \\
\text { in clinical } \\
\text { departments }\end{array}$ & $\begin{array}{l}\text { Success/ } \\
\text { Non- } \\
\text { success }\end{array}$ \\
\hline S1 & 34 & Physician & $\begin{array}{l}\text { Still in } \\
\text { clinical } \\
\text { pracitice }\end{array}$ & $\begin{array}{l}\text { Doctor in } \\
\text { Corona Test } \\
\text { Center }\end{array}$ & 5 & Success \\
\hline S2 & 61 & Physiotherapist & $\begin{array}{l}\text { Still in } \\
\text { clinical } \\
\text { practice }\end{array}$ & $\begin{array}{l}\text { Cleaner/Foodie/ } \\
\text { Runner }\end{array}$ & 15 & Success \\
\hline S3 & 63 & Physician & $>5$ & $\begin{array}{l}\text { Doctor in } \\
\text { Corona Test } \\
\text { Center }\end{array}$ & 3 & $\begin{array}{l}\text { Non- } \\
\text { success }\end{array}$ \\
\hline S4 & 30 & Physician/researcher & $<1$ & $\begin{array}{l}\text { Clinical doctor } \\
\text { corresponding } \\
\text { to a newly } \\
\text { educated doctor }\end{array}$ & 5 & Success \\
\hline S5 & 35 & Physician/researcher & $<1$ & $\begin{array}{l}\text { Doctor in } \\
\text { Corona Test } \\
\text { Center }\end{array}$ & 2 & $\begin{array}{l}\text { Non- } \\
\text { success }\end{array}$ \\
\hline S6 & 57 & $\begin{array}{l}\text { Master of Science } \\
(\mathrm{MSc})\end{array}$ & $\begin{array}{l}\text { Never in } \\
\text { clinical } \\
\text { practice }\end{array}$ & Runner & 4 & Success \\
\hline
\end{tabular}

From the 14 interviews we identified several moderating factors related to the dynamics of reallocating staff from departments with reduced activities to COVID-19 test center or bed section during the first wave of the pandemic. We categorized the factors as structural, perceptional, personal, social, and psychological factors. Table 3 provides an overview of the five categories and subcategories. 
Table 3

Categories and subcategories

\begin{tabular}{|ll|}
\hline Category & Subcategory \\
\hline Structural factors & Work schedules and planning \\
\hline Resource management \\
\hline Coverage of expenses \\
\hline Educational set-up \\
\hline Introduction to the unit and tasks \\
\hline Social factors & $\begin{array}{l}\text { Perception of the departments' role in the pandemic } \\
\text { Volunteering or not? }\end{array}$ \\
\hline Sense of urgency \\
\hline Use of network \\
\hline Being an asset for the hospital/corporate spirit \\
\hline The feeling of being needed and appreciated \\
\hline Natural selection \\
\hline Once a clinician, not always a clinician \\
\hline Navigating in a new organization \\
\hline Knowing the hospital and the new department \\
\hline Uncertainty leads to insecurity \\
\hline Unfamiliar tasks \\
\hline Transparency leads to security \\
\hline Collegial sparring creates confidence \\
\hline A regular workplace creates certainty \\
\hline Management dilemmas \\
\hline factors
\end{tabular}

\section{Structural factors}

Identified moderating factors were categorized as structural factors if they were related to the contingency plan set-up, such as work schedules, financial structures, and educational- and organizational set-up.

\subsection{Work schedules and planning}


When staff were needed to cover a shift, a text message offering the shift was sent to all staff reallocated to the floating pool, which they could then accept or decline. The first person to accept the shift received a confirmation, whereas the rest did not get further information. Some informants perceived the procedure with a text message as a flexible solution. Others found it difficult to plan ahead and get an overview of which shifts had already been taken. Furthermore, it could be difficult for the staff to know to what extent they should prioritize the shift over their usual tasks. In addition, the flexibility was challenged by schools and childcare institutions being closed during the first wave of the pandemic.

"The text message worked well. Or in general it worked well. Sometimes you were offered 10, maybe 15 different shifts, and even though you replied quickly, you might not get the 3 shifts you wanted and were left with shifts that did not match with your family or other tasks [...] It would have been nice with more transparency."

(S1, success, physician, Corona Test Center)

Not all staff had been properly informed about the registration procedure. Several informants had expected a fixed work schedule or expected to be reallocated to only one department. They were also insecure about how many shifts they were expected to cover.

"I received a text message. But I didn't know if it was because they needed me, or if there were any other volunteers. We thought they would give us a work schedule, but that was not the case. (S5, non-success, physician, Corona Test Center)

The uncertainty about signing up for shifts led some informants to seek out shifts themselves.

"I thought registration would be automatic and I would hear from them, but I didn't. So I just showed up at the floating pool agency and got my shifts planned"

(S6, success, MSc, runner)

\subsection{Resource management}

Although most of the staff were sent home due to the COVID-19 restrictions, they were not necessarily available for reallocation. The departments needed to retain some staff to secure day-to-day operations. Also, some of the departments had tasks directly related to handling COVID-19, which required retainment of staff. Thus, what in theory looked like staff that could be reallocated, was not in practice.

"Suddenly we had a lot to do, and I couldn't just say that everybody could cover [COVID-19] shifts. So I retained staff" (L 1)

The staff's experience with being reallocated was affected by how the pandemic influenced usual tasks. For example, some staff could easily carry out usual tasks from home, and to them the clinical shifts were perceived to be an add-on, whereas others did not experience a conflict with usual tasks. 
"To me it was all about, how does it affect my everyday life? How does it affect my family and my usual work? It was extra work. It was hard to fit my schedule"

(S5, non-success, physician, Corona Test Center)

"Professionally, it felt more relevant for me to be at the hospital, than to sit at home"

(S4, success, physician, clinical doctor)

The staff contingency plan did not outline the order in which staff should be prioritized for shifts, and often the text message with an available shift was sent out to a large group of staff without consideration of prioritization.

"I needed an order of priority, so that those of us who could work from home, did not have to be the first to be reallocated." (S5, non-success, physician, Corona Test Center)

In addition, shifts were offered to the staff directly, without involving their leaders. This feature made it difficult for the leaders to form a general view of which staff were available for other tasks and prioritize which staff should be reallocated. This led to a feeling of poor utilization of resources among leaders and staff.

"It became much more expensive than necessary. A lot of staff were sent home. But we had no control over which staff were offered and accepted a shift. It was unclear whether it was 'nice to' or 'need to'. It became like pick'n'mix sweets, without my involvement. It did not make sense, financially." (L1)

"Many physicians could have taken shifts but were just at home waiting. We could have utilized the resources better. Other departments had physicians with lots of work overload, and we had physicians to spare." (L5)

\subsection{Coverage of expenses}

The departments were expected to cover the salary expenses of their staff while reallocated, as shifts were meant to replace ordinary work and not to be extra work. The reallocated staff usually only worked daytime, but often the COVID-19 shifts were evening- or night shifts. The expenses became a big concern for some leaders as the departments had not budgeted with shift allowances. As a result, one of the informants experienced restrictions on which shift she was allowed to cover.

"Many of the shifts offered from the floating pool were evening or night shifts, but we were told only to accept day shifts if we usually only had day shifts. Or else, I could have taken more shifts"(S6, success, MSc, runner)

Coverage of expenses was also a challenge for staff whose salary was covered by funds, such as Ph.D. students. For this type of staff, the departments had to cover all expenses. 


\subsection{Educational set-up}

As preparation, the staff participated in a one-day course, providing theoretical knowledge, a brush-up on clinical skills and brief introduction to new COVID-related tasks. When possible, the staff were offered a tour in the COVID-19 test center. Most informants believed that practical training was superior to theoretical sessions.

"It was nice to see the location, see the forms we should use, be introduced to the actual task on a practical level instead of on a theoretical level."

(S1, success, physician, Corona Test Center)

"If you are to train people in how to use protective equipment, you don't just tell them and show a video. You get people to try it themselves again and again." (S3, non-success, physician, Corona Test Center)

\subsection{Introduction to the unit and tasks}

There was a variation in how the staff were introduced to the unit they were reallocated to. Some of the reallocated staff experienced that the permanent staff did not know they were coming or were unaware of which tasks the reallocated staff could take on.

"' 'Oh, are you here today? We don't need you on duty, we already have enough staff.' Well okay, thanks for calling me in on a Saturday [ironic tone of voice]"

(S5, non-success, physician, Corona Test Center)

"I got a list of which tasks 'the cleaner' was expected to do. However, the tasks were described in very general terms, so I had to define them myself. I followed another 'cleaner' around the first couple of times, but everyone was like: 'what are we doing here, what are we supposed to do?' Nobody instructed me in what to do"

(S2, success, therapist, cleaner/ foodie/ runner)

Opposite, some of the reallocated staff experienced a very organized and detailed introduction to the unit.

"I received all the introduction material intented for new employees in the unit. It was very helpful. Some things had been changed since I last worked in the unit, such as the location of the on-call room. The physician in charge of education sent me everything they usually hand out to new colleagues in the unit" (S4, success, physician, clinical doctor)

\section{Perceptional factors}

Some of the factors that modified whether staff were successfully reallocated were related to how staff and the leaders interpreted the staff contingency plan in the context of their own understanding. These factors were categorized as perceptional factors. 
How the leaders perceived the departments' role in the contingency plan influenced their expectations of the involvement of their staff. All leaders were ready to contribute with staff, but many leaders did not think of their department as the first choice, as they perceived the department to be different from other departments.

"We are a special department [...] a department like ours is not the obvious choice to be in the front row" (L1)

"We are part of the hospital, but we are different... we are not the ones who stand first in line" (L8)

\subsection{Volunteering or not?}

It was unclear to the leaders whether participation was voluntary or not, and this affected how they framed reallocation to their staff. Several leaders framed reallocation as voluntary, especially if they did not perceive their staff as the obvious first choice.

"I decided that it was voluntary. So I didn't put any pressure on the staff" (L8)

"It was important that the staff were motivated and wanted to participate. They were not forced if they had any concerns" (L3)

Opposite, some leaders perceived their staff to be first in line and had already early in the process proactively offered to reallocate staff as part of the hospital crisis management. They framed participation as a duty.

"I told the staff that we are part of the hospital, so if there is a crisis, we will be ready. Therefore, the staff might have felt it was mandatory, because that was what l expressed." (L7)

The reallocated staff had diverse experiences concerning whether they had felt pressured into participating in the reallocation. Some of them had experienced the reallocation as completely voluntary, whereas others had felt an expectation from their leader or the hospital management.

"We were told that we wouldn't be forced, but we were encouraged." (S6, success, MSc, runner)

"I felt a pressure. Not from my own management, but from the hospital. 'All of you who are not having 'a real job' - get in the game' "

(S5, non-success, physician, Corona Test Center)

\subsection{Sense of urgency}

The sense of urgency experienced by both staff and leaders, influenced their motivation and behavior, in particular in the beginning of the first wave of the pandemic.

"It was a burning platform, everybody wanted to help... to go out and save lives" (L6) 
"It was a time with constant updates from Italy lthe country that experienced a serious outbreak of COVID19]. So of course we wanted to help in that situation. That was the overall response". (S4, success, physician, clinical doctor)

However, as the first wave of the COVID-19 pandemic evolved, the sense of urgency changed. The pandemic seemed to be under control, and consequently the burning platform became less apparent.

"The sense of urgency was gone" (L8)

Some leaders experienced staff who were frustrated because they had accepted a shift, but there had been nothing to do. Others experienced having available staff but no demand from the clinical units.

"Almost every day I would say; 'oh you didn't get a shift'" (L7)

"There was no need for my help. I only covered three shifts."

(S5, non-success, physician, Corona Test Center)

\section{Social factors}

The process of reallocation was perceived by the leaders and staff in a social context. Therefore, factors related to the social context such as leaders' and staff's use of their network in the hospital, the corporate spirit and the feeling of being appreciated were categorized as social factors.

\subsection{Use of network}

The relationship to the hospital management, the management of the floating pool agency etc. influenced how the leaders overcame the challenges with shift planning and lack of transparency in structural factors. Some leaders used their network and made individual agreements about reallocation of staff, which resulted in a better balance between the demand for reallocation and the need for staff to secure day-to-day operations in the department.

"We had a close relationship with the management of the floating pool. They asked us directly for available staff when needed. In that way, we were able to fit the shift planning" (L4)

\subsection{Corporate spirit}

It was important for the leaders to actively participate in the crisis management. It was a societal crisis which put the hospital under tremendous pressure. The leaders all felt an obligation and motivation to contribute as they felt a sense of cohesion with the rest of the hospital.

"It was very important in our department that we could contribute and be an asset for this hospital" (L7)

"I was very focused on showing how my department could contribute, at a time when the regular bureaucracy was disabled. It was important to me that we did not just sit by when the rest of the hospital 
was busy" (L2)

The feeling of cohesion and sense of urgency promoted a proactive behavior among the leaders. For example, several leaders independently offered their contribution before the staff contingency plan was developed.

"I had already told the CEOs of the hospital that we had many physicians available. We were ready to contribute. I had already told my staff that they should expect changes, and that their work tasks could change radically" $(L 7)$

"We contacted the clinical departments and made lists of which tasks our staff could fulfill. We were planning long before. For example, could we fetch water to the patients? We could just as well help out in the departments we were familiar with" $(L 6)$

Several leaders also expressed a willingness to participate in the reallocation themselves.

"If the situation escalates and the clinical staff cry for help, we all need to put on the uniform." (L2)

"All hands on deck" (L8)

\subsection{The feeling of being needed and appreciated}

The feeling of being needed influenced the reallocation experience positively. The staff who had a positive experience with being reallocated all felt that their contribution made a difference and was appreciated by the clinical staff.

"Did it make a difference?, Yes I think so. I think the [clinical] staff thought it was helpful when I picked up things for them, so they did not have to change protective equipment. Of course, they spent some time telling me how to do things, but it would have taken longer if they had to do it themselves" (S6, success, MSc, runner)

"It made a difference that the clinical staff could save lives while we were helping out behind the scene"

(S2, success, therapist, cleaner/foodie/runner)

Several of the reallocated staff experienced positive comments, which influenced their experience positively and added to the feeling of being needed.

"What made it a positive experience, was the feeling of doing something important to other people. When I was in the Corona Test Center, I was in contact with many different people, and I often had comments like; 'Good Job'. That made me feel good"

(S6, success, MSc, runner)

\section{Individual factors}


Whether staff were successfully reallocated was influenced by individual factors, meaning factors related to personal characteristics, health and skills.

\subsection{Natural selection}

Staff were not reallocated if they had any health issues. The leaders did not have any predefined criteria, but typically staff with chronic diseases, pregnancy, and older staff, and also staff who were concerned for their own health were excepted from reallocation.

"Staff who were concerned for their health were not selected for reallocation. And nobody questioned it" (L6)

"Our group of doctors are typically seniors, and some have chronic diseases. We had to split the group so that the senior doctors were retained, and the junior doctors were reallocated." (L4)

\subsection{Once a clinician, not always a clinician}

For a large group of the staff, it had been many years since they had worked in the clinical setting. Many of them had deliberately chosen a career that did not involve any clinical work. This was also a consideration that the leaders had to take into account.

"The nurses in my department work there for a reason: because they don't want to work as nurses." (L8) "For some, being in clinical practice led to anxiety. Some choose our specialty because they don't want a life as a doctor." ( $L 7)$

Some of the reallocated staff had reflected on their skills and competencies, and also what kind of functions they would feel comfortable being assigned to.

"I did consider to be reallocated to a resident position, but I have not worked in a clinical department the last five to six years. So I decided not to do that"

(S1, success, physician, Corona Test Center)

"To me, a great barrier was fear. Am I skilled enough to do this?

(S5, non-success, physician, Corona Test Center)

\subsection{Navigating in a new organization}

Many of the staff were reallocated to the newly established test center for COVID-19 The test center was developed continuously during the first wave, which affected the staff's experience. The staff described shifts in the test center as being chaotic in the beginning. They experienced a lack of leadership and information. Roles were undefined and nobody assigned tasks to the staff. The staff had to deal with constant changes as workflows, guidelines, and the national test strategy continuously changed. 
"I experienced chaos, medical students that had never been there before. Everyone was new. If you had been there twice, you were experienced."

(S5, non-success, physician, Corona Test Center)

"I never understood the organization, and I never managed to figure out who had the authority to make decisions." (S3, non-success, physician, Corona Test Center)

How the reallocated staff experienced the dynamic environment varied. For some it led to frustration or insecurity, others were unaffected and just positively coped with it.

"It was fine to just cover one shift per week. One time I covered two shifts with a few days in between, but it made no difference, everything had been changed. It became a routine to ask the secretary or nurse about what had been changed since the last shift." ( 1 1, success, physician, Corona Test Center)

"It was new territory for everyone... and maybe that's why everyone was so forthcoming. It might have been harder to be reallocated to a unit with permanent staff"

(S6, success, MSc, runner)

4.4 Knowing the hospital and the new department

Knowledge of the hospital and the new department affected how the staff experienced being reallocated. Knowledge of the department or unit made the staff feel more comfortable and enabled them to concentrate on doing their tasks.

"I think it was easy because I knew the hospital and the unit. It wasn't so difficult for me to go back to clinical practice. The first shift was an evening/night shift, and it's been two years since I was there last time. But there were lots of people I knew, which was nice"

(S4, success, physician, clinical doctor)

Staff who had no previous knowledge of the unit had to spend time and energy to figure out the workflows and use of local professional language. It was not always easy to ask the permanent staff for help when things were busy, and often abbreviations were used which made no sense to the reallocated staff.

"[The list of units and persons to call if in need of help] could have been more specified. Those who usually work in the departments know the different medical expressions used in their speciality, but to me it was gibberish. Also, I did not know who to call" (S5, non-success, physician, Corona Test Center)

"The biggest frustration about not knowing the units you are reallocated to, is that you don't know where to find things. I had to ask several times; 'excuse me, where do I find...?' "(S2, success, therapist, cleaner/foodie/runner) 


\section{Psychological factors}

Moderating factors were categorized as psychological factors if they resulted in an emotional response.

In general, psychological safety was a recurring theme throughout the interviews with both staff and leaders.

"First of all, you have to feel safe, or else you cannot help others" (S1, success, physician, Corona Test Center)

\subsection{Uncertainty leads to insecurity}

The uncertainty about tasks and what was expected of them made some of the reallocated staff feel insecure about being reallocated.

"The experience of being on shift was alright. It was the circumstances that surprised me. You were not sure of the tasks and you did not know what you could be exposed to" (S5, non-success, physician, Corona Test Center)

In addition, the stories about what could happen on a shift added to the uncertainty and anticipatory anxiety.

"You hear rumours about cardiac arrest and critically ill patients."

(S5, non-success, physician, Corona Test Center)

When the staff knew what to expect, they did not feel insecure about being reallocated.

Knowing what I know now, I would not mind being reallocated again"

(S5, non-success, physician, Corona Test Center)

One of the reallocated staff talked about being reallocated to her prior place of employment.

"It's always difficult being out of clinical practice for two and a half years and having to start thinking as a clinician again. This hospital treats severely ill patients. But I knew what I went into, so it wasn't a surprise to me. But I still need to dust off my old knowledge"

(S4, success, physician, clinical doctor)

As pointed out by the leaders, the staff coped with their uncertainty in different ways.

"Some people are able to contain uncertainty very well, and others need clear arrangements. [...] For the staff who need clear arrangements, it was a difficult period. And then you have the kind of people who just say 'well, that sounds exciting'" (L7) 


\subsection{Unfamiliar tasks}

A lot of the tasks that the reallocated staff were given were unfamiliar, and sometimes they were unsure of the professional standards. In certain situations, some staff expressed concerns about whether they could perform their tasks properly, e.g. assisting with sampling of tests;

"The only thing I was insecure about was the throat swab [...] It was probably just me, feeling outside my comfort zone." (S6, success, MSc, runner)

Despite insecurity about the tasks, the staff with an overall good experience emphasized that colleagues being forthcoming, introducing them to the tasks, and correcting potential errors made them feel less unsure.

"If I made a mistake, my colleagues would tell me." (S6, success, MSc, runner)

\subsection{Transparency leads to security}

At the time when the staff were reallocated, there was a lack of knowledge of the actual tasks and what the staff could be exposed to, which led to frustration. For some of the reallocated staff, transparency and honesty were important contributors to accepting the uncertainty and having a positive experience with being reallocated.

"There were two chief physicians on call you could always ask. They were always honest; 'I don't know. I'll get back to you.' The transparency was nice. As long as you got an honest answer, you knew that you just had to buckle down"

(S1, success, physician, Corona Test Center)

\subsection{Collegial sparring creates confidence}

The reallocated staff emphasized the importance of sparring with colleagues which made them feel more confident in their new assignment. Several of the staff expressed that it was legitimate to ask questions, and that collegial sparring was always available.

"It also made me feel confident that there was always a doctor in the ward with whom you could discuss the patients. I felt that everybody was very forthcoming. Sometimes the medical specialists also asked me for advice. And sometimes I asked them. There was a constant exchange of information [...] There was a willingness to talk to each other. Nobody snapped our heads off." (S1, success, physician, Corona Test Center)

\subsection{A regular workplace creates certainty}

Becoming familiar with a new unit and new tasks increased the reallocated staff's confidence. 
"Being assigned to one specific unit made me feel more confident, and I knew my way around the unit. So I said to the floating pool agency that it would be easier if I stayed at that unit." (S2, success, therapist, cleaner/foodie/runner)

The staff also expressed that a regular workplace was not only a personal advantage but also an advantage for the permanent staff on the ward, because they had to spend less time introducing new staff.

\subsection{Management dilemmas}

Some of the leaders experienced dilemmas concerning the reallocation of staff. For some it had not been an easy choice whether reallocation should be voluntary or not. Also, the leaders were concerned about how their staff would react to being reallocated.

It was difficult as a leader. Should I force them to reallocate? It would probably have had some consequences" (L8)

"I was a bit concerned about how to tell the junior doctors that the senior doctors could stay at home and relax while they had to be sent into the lion's den. However, it was never an issue for the junior doctors."

\section{Discussion}

In this study, we found that execution of a staff contingency plan during a pandemic was influenced by a complex set of structural, perceptional, social, individual, and psychological moderating factors.

Previous studies have mainly focused on staff's willingness to work during a pandemic as an essential determinant of securing workforce capacity $(3,5)$. Lee et al. refer to willingness as "an individual's openness to opportunity" (5). This understanding of human behavior is found in models such as 'the Integrated Behavioral Model', which underlines behavior as an intentional act (17) - in this case, intention or wanting to provide care for patients (5). In our study we included highly motivated staff and still found barriers to work. We also included a leadership perspective to better understand the incentives that hindered or promoted successful reallocation. Similarly to previous studies, we found that uncertainty about tasks, the feeling of being needed, reflections on personal skills, the feeling of sense of urgency and social responsibility, family obligations, and experience with the clinical unit influenced the decision and experience of being reallocated to clinical practice during the COVID-19 pandemic. However, in our study we also found that even though staff felt obligated and motivated to work and intended to cover shifts, their actual behavior was influenced by several other factors related to the contingency plan set-up, how the contingency plan and roles were interpreted by staff and leaders, and how the leaders prioritized tasks and staff time. In our study shift planning was a major theme for both leaders and staff. The procedure for on-duty scheduling influenced how the staff signed up for shifts and how human resources were 
utilized at hospital level. This finding highlights the importance of understanding structural barriers when formulating staff contingency plans.

We also found that staff and leaders navigated the system and tried to adjust to the situation, for example when the leaders made individual arrangements with the management of the floating pool to sustain control of their staff. Also, as the sense of urgency declined, the leaders and staff adjusted to the situation. Some adjustments may benefit the overall shared goal of handling the crisis efficiently, whereas other adjustments may be counterproductive. It is important to understand how staff and leaders make interpretations and adjustments to a given plan. This can only be studied when the plan is in action, and therefore, future staff contingency plans should consider how to evaluate such dynamics real-time to be able to improve the plan.

Lack of PPE was a big concern at the hospital during the first wave of COVID-19. However, contrary to other studies $(5,18-20)$, fear of infection and lack of PPE was not a major theme in our interviews. Instead, the staff talked about insecurity related to the tasks and the new organization. However, this inconsistency does not equal that fear of infection was not a moderating factor. Leaders prioritized staff based on assessed risk to the individual, and thus, staff that may have feared for their own safety or were categorized as high risk population were never considered or signed up for reallocation and therefore not part of the study population.

The ethics of reallocation of staff during the COVID-19 pandemic has been discussed by Dunn et al., who argue that the decision to reallocate health professionals should include considerations regarding; 1 ) which staff are chosen to be reallocated; 2) justifiable reallocation models; 3 ) what is owed to the reallocated staff (21). First, in our study the leaders experienced a dilemma when choosing which staff to reallocate. The leaders expressed how they had to balance individual risks, skills and competencies. Many of the staff had deliberately chosen a career that did not involve clinical work. The staff contingency plan did not include an explicit priority of who should be first in line to be reallocated. Consequently, many of the leaders made decisions based on their interpretation of how their staff and department fitted the contingency plan. Secondly, when choosing a justifiable reallocation model, the leaders interpreted the request from the hospital management differently, which resulted in diverse outcomes, as some leaders expected their staff to participate in the reallocation and others decided that reallocation was voluntary. For the leaders who expected their staff to participate in reallocation, the decision was based on an argument of duty. This is in line with other studies which have described how healthcare professionals did what they felt was morally right (20). They believed it to be their duty as healthcare workers to care for patients infected with coronavirus $(18,22)$. Nevertheless, as described by Halberg et al., duty does not equal volunteering (22). Dunn et al. ague that a model of 'no choice' may be efficient but is arguably unethical, as it does not allow the staff to retain control over their job and risk of infection in clinical practice (21). However, in our study the contingency plan set-up made it possible for the staff to bypass the expectation of reallocation as they could decline or ignore a request for a shift on a text message. In this way, the staff retained control. Most of the leaders chose an explicit model of 'individual choice', in which they perceived reallocation to be voluntary. However, even though reallocation was framed as 
voluntary, some staff still expressed a social pressure to reallocate. In line with this, Tousgaard et al. found that nursing staff described different degrees of volunteering during COVID-19, as some nurses chose to participate because they wanted to help, whereas others experienced an implied expectation from their management (23). Dunn et al. argue that volunteering is a more ethical option, but it permits potential unfairness, as those who do not accept shifts potentially free ride on the good will of their colleagues (21). Thirdly, concerning what is owed to the reallocated staff (21), previous studies underline the importance of outbreak-specific training to improve outbreak knowledge and skills and increase selfefficacy (5). In our study all the staff participated in a one-day course. In general, the participants found practical training to be superior to theoretical training. We also found that introduction to the specific unit and tasks influenced the experience positively. The reallocated staff used a lot of energy when they tried to navigate the workflows and understand the local professional language used. These findings underline the importance of ensuring outbreak-specific introduction when reallocating staff during a pandemic, not only in terms of outbreak-specific knowledge but also introduction to the unit, colleagues, and often used abbreviations and terms. However, during a pandemic, it may be a challenge to conduct such training as the situation keeps changing as the pandemic evolves, and due to risk of infection. In such circumstances, a psychologically safe environment, in which it is legitimate to ask questions may reduce stress and increase the feeling of safety. Edmondson et al. define 'psychological safety' as people's perception of the consequences of taking interpersonal risks in a particular context. A psychologically safe environment is characterized by staff not being afraid of asking questions or expressing concerns. Instead, staff seek information exchange with others, which fosters a trusting relationship. Focus is on the collective goal rather than on self-protection (24). In our study, the reallocated staff emphasized the importance of collegial sparring and transparency. They also highlighted a feeling of mutual respect and trusted that colleagues would speak up if they made a mistake. It is interesting how the staff experienced insecurity about tasks, chaos, and lack of leadership, especially in the newly established test center, and at the same time expressed a high degree of psychological safety. In the Corona Test Center, everyone was new to the work, and no interpersonal hierarchy existed. This may have led to a shared understanding of the importance of mutual support. Also, the staff in our study may have felt less need to protect their own professional identity, as they did not usually work in a clinical setting and therefore may have felt that it was more legitimate to be open about their own limitations.

\section{Strengths and limitations}

In this mixed-method study, we chose an explanatory design with a main focus on the qualitative results. By putting more weight on the survey results, we could have obtained information on the complete group of respondents instead of only focusing on the extremes. However, the main purpose of this study was to explore factors that contributed positively as well as negatively to the success of reallocation. Due to the limited knowledge in this field, we believe that the qualitative approach would provide more in-depth knowledge, as argued by Lee et al. (5).

The interviews with the staff were inspired by Brinkerhoff's Success Case Method $(9,10)$, which was applied in the sampling process (successes and non-successes) and in developing the interview guide. In 
this study, we chose to apply the SCM differently than intended by Brinkerhoff, since our main focus was not on the business effect of training (9). However, we believe that the SCM was applicable and helped us shed light on the factors contributing to the dynamics of reallocation of staff during the first wave of COVID-19. One of the advantages of the SCM is the focus on using the extremes to provide knowledge of the factors that contribute to a successful reallocation, as well as to the factors that lead to a negative experience with reallocation. This helped us obtain a broad view of contributing factors, which may increase the trustworthiness and credibility of the study $(25,26)$. In our study we defined a success as a participant who had had a positive experience with being reallocated. Another way of defining a success could have been based on the actual number of shifts covered, which potentially could have led to other insights. We did not compare successes and non-successes with regard to specific factors, as it became clear that many barriers and promoters affected both groups, and whether staff ended up having a shift was determined by a complex set of factors.

Selecting participants with diverse usual job functions and assigned new job functions may also strengthen the credibility and sampling sufficiency $(25,26)$. Other hospitals may have chosen to execute their staff contingency plan differently, which could impede the application of these results. However, to increase the transferability of the results, we have attached great importance to providing a rich description of the findings and use of quotations (27).

We used inductive content analysis to analyze our data, which enables obtaining results based on the participants' perspectives without imposing preconceived categories $(16,28)$. However, the risk of using an inductive approach is failure to identify key categories, which may threaten the credibility of the study (28). Therefore, we have sought to strengthen the credibility using researcher triangulation (29). Data was analyzed by two researchers (RLRJ and CE) with different educational backgrounds (public health science and nursing science) and discussed with the rest of the research group, providing more perspectives to analysis and discussion $(16,27)$.

This study explored the dynamics of reallocation of staff during the first wave of COVID-19, incorporating the perspective of both the staff and their leaders. In line with Brinkerhoff's Success Case Method, another important perspective is whether this reallocation was actually valuable to the clinical departments taking in reallocated staff. Originally, we incorporated this perspective in the design of the study. Due to the time frame of the study, we only succeeded in interviewing two leaders from departments receiving help from the reallocated staff. As data was limited, we chose not to include the results in this study. However, one of the important points from these interviews was that although the reallocation of staff could be helpful, introducing them to the clinical setting was time- and resource consuming for both leaders and the regular staff. Consequently, the leaders preferred to use their regular staff or regular substitutes to cover the new functions. This may be a contributing factor in terms of why the staff did not get reallocated to the expected extent during the first wave of the pandemic.

Lastly, one of the main strengths of this study is, that it takes on a different perspective than many of the existing studies focusing on the frontline staff only. By focusing on the staff and leadership perspectives 
we gain a better understanding of the barriers and promoters of the reallocation of staff, which may be important in future contingency plans.

\section{Conclusion}

This study sheds light on the dynamics of a reallocation process of staff during the first wave of the COVID-19 pandemic. Although the contingency plan was designed to fit the organization and needs of our hospital, this study underlines how reallocation is affected by a complex set of structural, perceptional, social, individual, and psychological moderating factors, which should be considered when hospital contingency plans are developed. A central finding is the importance of understanding structural barriers such as leaders' prioritization of tasks and staff time, and also the organizational and financial framework of staff reallocation. Furthermore, it is important to understand how reallocated staff and leaders make interpretations and adjustments to a given plan, as this may have great significance for how the contingency plan is put into practice. Future staff contingency plans should take these factors into consideration to make better use of human resources in times of a crisis and to improve staff experience with reallocation.

\section{Declarations}

\section{Acknowledgements}

The authors would like to thank the staff and leaders participating in this study.

\section{Authors' contribution}

RLRJ, AS, MSJ, KHM and CE all contributed to the design of the study. RLRJ and CE conducted the interviews, analyzed the data and drafted the manuscript. All authors read, revised, and approved the final manuscript.

\section{Funding}

This study has not received any funding. MSJ reports having received research funding for his department from Merck Sharp \& Dohme for research outside the submitted work. The Department of Quality and Education, Bispebjerg and Frederiksberg University Hospital financed the publishing of the study.

\section{Availability of data and materials}

The datasets generated and analysed during the current study are not publicly available as it is not possible to anonymize the original sound files and the files have not been fully transcribed. All materials 


\section{Ethics approval and consent to participate}

Informed consent was obtained from all informants. According to Danish law, only biomedical research requires permission from the Regional Scientific Ethical Committee $(30,31)$. Furthermore, the research group requested permission from the Danish Data Protection Agency, but this was not required.

\section{Consent for publication}

Not applicable.

\section{Competing interests}

The authors declare that they have no competing interests.

\section{References}

1. Danish Health Authority. Danish Health Authority 2020. COVID-19 in Denmark. First wave of the epidemic. Status and strategy 2020; Available at: https://www.sst.dk/-/media/Nyheder/2020/COVID19-i-Danmark_-Epidemiens-foerste-boelge_-Status-og-Strategi_-Version-23_-marts-2020.ashx? la=da\&hash=263A3D8EAB851F406EAA6DA81D6EA91A64F1A087 Accessed on 17 Dec 2021.

2. World Health Organization. COVID-19 strategy update. 2020; Available at: https://www.who.int/publications/m/item/covid-19-strategy-update. Accessed on 1 Dec 2021.

3. Aoyagi Y, Beck CR, Dingwall R, Nguyen-Van-Tam JS. Healthcare workers' willingness to work during an influenza pandemic: a systematic review and meta-analysis. Influenza Other Respir Viruses. 2015;9(3):120-30.

4. World Health Organization. COVID-19: operational guidance for maintaining essential health services during an outbreak: interim guidance, 25 March 2020. 2020; Available at: https://apps.who.int/iris/handle/10665/331561. Accessed on 1 Dec 2021.

5. Lee HJ, Kim E, Morse BL, Lee SE. Barriers and Facilitators of Nurses' and Physicians' Willingness to Work during a Respiratory Disease Outbreak: A Mixed-Methods Systematic Review. Int J Environ Res Public Health. 2021;18(13):6841.

6. Fetters MD, Curry LA, Creswell JW. Achieving integration in mixed methods designs - principles and practices. Health Serv Res. 2013;48(6 Pt 2):2134-56.

7. Creswell J, Plano-Clark V. Choosing a mixed methods design. In Designing and conducting mixed methods research. Thousand Oaks: SAGE Publications;2007:58-88. 
8. Corbin J, Strauss A. Introduction. In Basics of qualitative research. Techniques and procedures for developing Grounded Theory. 3rd ed. Thousand Oaks: SAGE Publications; 2008:1-17.

9. Brinkerhoff RO. The Success Case Method: A Strategic Evaluation Approach to Increasing the Value and Effect of Training. Adv Dev Hum Resour. 2005;7:86-101.

10. Brinkerhoff RO. The Success Case Method. San Francisco: Berrett-Koehler Publishers; 2003.

11. Eid A, Quinn D. Factors predicting training transfer in health professionals participating in quality improvement educational interventions. BMC Med Educ. 2017;17(1):26.

12. Olson CA, Shershneva MB, Brownstein MH. Peering inside the clock: using success case method to determine how and why practice-based educational interventions succed. $J$ Contin Educ Health Prof. 2011;31(1):50-59.

13. Shershneva MB, Larrison C, Robertson S, Speight M. Evaluation of a collaborative program on smoking cessation: translating outcomes framework into practice. J Contin Educ Health Prof. 2011;31( 1):28-36.

14. Kvale S, Brinkmann S. Interviews. Learning the craft of qualitative research interviewing. 2nd ed. London: SAGE Publications; 2009.

15. Robson C, McCartan K. Interviews and focus groups. In: Real world research. A resource for users of social research methods in applied settings. 4th ed. West Sussex: John Wiley \& Sons; 2016: 284306.

16. Elo S, Kyngäs H. The qualitative content analysis process. J Adv Nurs. 2008;62(1):107-15.

17. Montaño $D$, Kasprzyk $D$. Theory of reasoned action, theory of planned behavior, and the integrated behavioral model. In Health Behavior: Theory, Research and Practice. Edited by Glanz K, Rimer B \& Viswanath K. 5th ed. San Francisco: Jossey-Bass/Wiley;2015:95-124.

18. Liu Q, Luo D, Haase JE, Guo Q, Wang XQ, Liu S,Xia L, Liu Z, Yang J, Yang BX. . The experiences of health-care providers during the COVID-19 crisis in China: a qualitative study. Lancet Glob Health. 2020;8(6):790-98.

19. Nabe-Nielsen K, Nilsson CJ, Juul-Madsen M, Bredal C, Hansen LOP, Hansen ÅM. COVID-19 risk management at the workplace, fear of infection and fear of transmission of infection among frontline employees. Occup Environ Med. 2021;78(4):248-54.

20. Marsaa K, Mendahl J, Heilman H, Johansson H, Husum M, Lippert D, Sandholm N, Konradsen H. Pride and Uncertainty: A Qualitative Study of Danish Nursing Staff in Temporary COVID-19 Wards. J Hosp Palliat Nurs. 2021;23(2):140-44.

21. Dunn M, Sheehan M, Hordern J, Turnham HL, Wilkinson D. "Your country needs you": The ethics of allocating staff to high-risk clinical roles in the management of patients with COVID-19. J Med Ethics. 2020;46(7):436-40.

22. Halberg N, Jensen PS, Larsen TS. We are not heroes - The flipside of the hero narrative amidst the COVID19-pandemic: A Danish hospital ethnography. J Adv Nurs. 2021;77(5):2429-36.

23. Tousgaard I, Paine MA, Olsen MG, Emme C. Good introduction and visible leadership, thank you. Fag Forsk. 2021;(1):26-35. 
24. Edmondson A. Psychological safety and learning behavior in work teams. Adm Sci Q. 1999;44(2):350-83.

25. Elo S, Kääriäinen M, Kanste O, Pölkki T, Utriainen K, Kyngäs H. Qualitative Content Analysis: A Focus on Trustworthiness. SAGE Open. 2014;1-10.

26. Morse JM, Barrett M, Mayan M, Olson K, Spiers J. Verification Strategies for Establishing Reliability and Validity in Qualitative Research. Int J Qual Methods. 2002:13-22.

27. Graneheim UH, Lundman B. Qualitative content analysis in nursing research: Concepts, procedures and measures to achieve trustworthiness. Nurse Educ Today. 2004;24(2):105-12.

28. Hsieh H-F, Shannon SE. Three approaches to qualitative content analysis. Qual Health Res. 2005;15(9):1277-88.

29. Carter N, Bryant-Lukosius D, DiCenso A, Blythe J, Neville AJ. The use of triangulation in qualitative research. Oncol Nurs Forum. 2014;41(5):545-7.

30. Retsinformation. Lov om videnskabsetisk behandling af sundhedsvidenskabelige forskningsprojekter. Available at: https://www.retsinformation.dk/eli/lta/2011/593. Accessed on 07 Jan 2022.

31. National Comitee on Health Research Ethics. Act on Research Ethics Review of Health Research Projects. Available at: https://en.nvk.dk/rules-and-guidelines/act-on-research-ethics-review-of-healthresearch-projects. Accessed on 07 Jan 2022. 